\title{
Creating and Hosting Student-Run Research Journals: A Case Study
}

\author{
Adrian K. Ho \\ Scholarly Communication Librarian \\ The University of Western Ontario \\ adrian.ho@uwo.ca
}

\begin{abstract}
This case study aims to examine an academic library's roles in facilitating the creation and hosting of open access student-run research journals. In addition to providing an online platform to host the journals, the library acquaints students with scholarly publishing, assists them in securing various resources available on campus, and offers support for content management. There are challenges and opportunities for the library as it undertakes the responsibility of hosting student journals. The article concludes with a discussion of possible topics for future research.
\end{abstract}

\section{Keywords}

student-run research journals; campus-based publishing; library publishing services; scholarly communication services; online journal hosting; scholarly communication outreach; student research; learning

\section{Introduction}

Education is at the core of a university's mission. Some institutions include research in their undergraduate curricula to sharpen students' analytical skills, strengthen their academic writing, and groom them for graduate studies. In an attempt to enrich students' academic experience and enhance the quality of education, such institutions pursue different avenues to engage undergraduate students in research. One of the strategies is to create a student-run research journal so that students will gain exposure to scholarly publishing by managing the journal and/or contributing to it. As shown by the list of undergraduate journals posted on the Web site of the Council on Undergraduate Research, this approach has been adopted by dozens of universities in the U.S., and some of the journals have been in existence for more than a decade. A search on the Directory of Open Access Journals reveals that free online journals have been developed at both graduate and undergraduate levels to publish outstanding student research.

In light of the scholarly publishing needs on campus, some academic libraries have started providing online publishing services for the dissemination of campus-based publications. Karla L. Hahn notes that some research libraries in 
Canada and the U.S. had already developed such services by late 2007 , and that they focused on publishing journals (13). Institutions' interest in creating student research journals and the emergence of academic libraries' publishing services have resulted in new partnerships on campus that expand the library's role in supporting learning and student research.

This article presents a case study in which the library at The University of Western Ontario (hereafter referred to as Western) has collaborated with different academic departments and faculties to launch open access student-run research journals. After the literature review, there will be a discussion of the library's roles and services in the hosting of the journals. The section that follows will examine challenges and opportunities for the library. The conclusion will address possible topics for future studies.

\section{Literature Review}

The creation of student research journals has been discussed in different disciplines. The journals, whether they are run by students or not, have garnered support and approval in general because they provide legitimate outlets for the publication and celebration of outstanding student research. Julie A. Pearson, Ronald L. VanNest, and Donna M. Jasinski note that a student journal in nurse anesthesia encourages contributors to review the professional literature and "consolidates efforts that students put forth to meet both didactic and clinical requirements" (68). In their discussion of student journals in psychology, Mark E. Ware and Susan R. Burns concisely present the benefits in terms of learning. Their arguments are echoed by Ariel Reno in her discussion of electronic undergraduate journals (5-9). In addition, Tabatha A. Farney and Suzanne L. Byerley report that faculty members have a favourable perception of such journals (325).

Some student journals are designed to be operated by students. It is noted that the students' participation in the journal production process is enormously beneficial to their intellectual growth. Benjamin J. Bauer et al., for example, contend that "[w]orking on a peer-reviewed journal presents students with a unique educational experience, one that provides continuous learning beyond the classroom setting and helps to refine research and editing skills" (565). They back the argument with an elaboration of the positive impact on students' critical thinking and interpersonal skills (567-568). John R. Jungck et al. highlight the significance of student-run journals in undergraduate education by stating that "[f]ull engagement and benefit in undergraduate research will not be realized until peer review and publication are standard expectations of these critical experiences" (24). They also enumerate the benefits for students who have participated in producing a journal (26). Daniel Antonius et al. point out that "[a] student-operated academic journal provides an innovative model for integrating research experience into applied psychology training" (32). A similar argument is 
raised in a discussion of deepening students' "understanding of political science as a field of study" (Benjamin J. Bauer et al. 567).

The fact that academic libraries function as publishers is not an entirely recent development. As Charles W. Bailey, Jr. recounts, one of the first online journals, The Public-Access Computer Systems Review, was launched and published by an academic library in August 1989 (n.p.). Similarly, Maria Anna Jankowska reports that the University of Idaho Library started publishing Electronic Green Journal in the summer of 1994 (120). Catherine Harboe-Ree states that academic libraries provide electronic publishing services because they are technologically capable and "have a desire to bring their values to bear on scholarly communication processes" (17). She argues that library publishers are more flexible due to the lack of oversight by advisory boards (23). Meanwhile, Linda L. Phillips asserts that research libraries' engagement in scholarly publishing is desirable because it facilitates access to their parent institutions' intellectual capital and can enhance the institutions' stature (156). Viewing from another perspective, Isaac Gilman and Marita Kunkel point out that collaborating with different constituents on campus to create and publish online journals is one of the strategies to change users' perceptions of the library and to demonstrate the library's value (28).

A report authored by Karla L. Hahn presents an insightful overview of publishing services provided by the member libraries of the Association of Research Libraries. She notes that such services are "pragmatic responses to evident needs" because they have been developed in response to scholars' requests (24). Their focus is on "the capabilities and possibilities of new models rather than slavishly duplicating or simply automating traditional models" (16). Eightyeight percent of the surveyed libraries have published journals, and the format of their publications is predominantly electronic. The funding for the services is usually sourced from the library budget (19). Faculty members have approached their libraries for the creation of student journals in order to engage students in scholarly research. They select the libraries as publishing partners because commercial publishers in general have little interest in publishing student works (24). Moreover, Jingfeng Xia remarks that some faculty members readily accept library publishing as an alternative to the traditional model of scholarly publishing because of such benefits as free online access, affordable hosting, and convenient management (373). It is, therefore, not surprising that faculty members have turned to their libraries for the creation of new student journals or for the hosting of existing ones if the libraries provide publishing services. 


\section{Creating and Hosting Student-Run Research Journals at Western}

\section{Student Journals at Western}

Western is a research-intensive university in London, Ontario, Canada. To showcase their student research, some academic departments have been publishing graduate and undergraduate student-run journals in print format since the 1990s. The library was not involved in the dissemination of the journals even though some of them were included in the library collections. Thanks to the emergence of scholarly communication as a new area of academic librarianship, the library articulated in the 2007/08-2010/11 strategic plan its commitment to raising the university community's awareness of new scholarly publishing models and thus created a new librarian position in 2008 (5-6). At the same time, the library licensed the Digital Commons platform from Berkeley Electronic Press for the dual purposes of creating an institutional repository and providing an online journal hosting service. The newly hired Scholarly Communication Librarian was assigned to set up and manage the platform. The institutional repository (Scholarship@Western) was launched in December 2008, and the discussion of a brand new open access student-run research journal ensued soon afterwards. ${ }^{1}$

While faculty members can be staunch advocates for the creation of student-run research journals, the experience at Western shows that enthusiastic students can equally take the lead to start up such journals. Indeed, most of the new student journals at Western were conceived and developed by ambitious graduate and undergraduate students who lamented that their departments did not offer an avenue to increase the visibility of outstanding student research. With the intention to further their studies and pursue a career in academia in the future, they were eager to create open access journals and to familiarize themselves with scholarly publishing practices by undertaking the responsibilities for running the journals. Thanks to referrals and library outreach activities, the students learned of the library's journal hosting service and contacted the Scholarly Communication Librarian for an exploration of possibilities.

\section{Library's Roles in Developing Student Journals}

The library is one of the stakeholders in the scholarly communication life cycle and has constant interaction with publishers, vendors, researchers, and readers. It is also an established unit that has built working relationships with different constituents on campus. Therefore, the library has much to offer when it comes to providing students with assistance in creating open access journals. Broadly speaking, the library's roles can be grouped into three categories. 


\section{Providing Assistance with Operational Planning}

Although the creation of a student journal hinges on students' commitment, the students sometimes may not be fully aware of the different issues and responsibilities entailed by developing and managing an open access journal. Marilyn Bittman, Lindsay Lynch, and Naomi Pauls mention that there are a wide variety of tasks involved in operating a journal (8). The tasks range from strategic planning and operational oversight to financial management, journal site maintenance, and promotion of the journal. They differ in nature and are divided up among a team of individuals who work closely to run the journal. As the Online Guide to Open Access Journals Publishing points out, it is crucial that the members of a journal team "understand what activities need to be carried out, who ought to carry them out and how they relate to other activities" (n.p.). This point is made unmistakably clear when Justin Hodgson stresses in his review of the development of an online journal on undergraduate multimedia scholarship that "no matter the system, no matter the approach, journals have always been a collaborative endeavor" (n.p.). To ensure that a student-run journal will take off and continue over time, the library has to educate the students about these issues and provide guidance as appropriate in the nascent stage of the journal. Specifically, the students have to understand that publishing a journal is a team effort, and that they need to recruit like-minded peers to fill the positions on the team and undertake the tasks involved in running the journal. Moreover, they have to acquire new skills in order to perform the responsibilities they assume. They also have to communicate with each other constantly in order to facilitate the collaboration. Before their terms conclude, they have to organize a new round of member recruitment, identify suitable students to run the journal in the next year, and properly hand over their responsibilities to their successors. Fortunately, there are handy resources for open access journal publishing that provide an overview of such topics, e.g., Developing Open Access Journals by David Solomon and Online Guide to Open Access Journals Publishing by CoAction Publishing and Lund University Libraries. Bringing them to the students' attention is highly beneficial in assisting them with the creation of their team and the planning for the journal. Meanwhile, it is important that they invite interested faculty members to participate in the process of developing the journal because the latter are able to provide advice and coach the students from the researcher's perspective. The involvement of faculty will also contribute to the continuity of the journal. As Richard L. Froman observes, "without commitment from key faculty members, the journal will not last long" (250).

In addition, the library can provide input in formulating journal policies. While the faculty members involved are familiar with certain journal publishing practices, they may not have a solid grasp of open access. This presents the library with a prime opportunity to fill both the students and the faculty members in on the rationale and practices of open access journal publishing. Moreover, an introduction to the basics of copyright law as well as Creative Commons licenses can illuminate the benefits of open access and how journal publishing is 
interwoven with teaching, learning, and scholarship advancement. It not only reveals the downsides of the copyright transfer requirement imposed by subscription-based journals but also highlights how authors' retention of copyright in their works can enhance the dissemination and reuse of their intellectual property. In other words, educating the students and the faculty members about open access and copyright issues lays the foundation on which the journal team develops policies and practices that optimize the journal's contribution to knowledge sharing. It also prepares the students for handling potential authors' questions about publishing their articles in an open access journal. However, the library's focus is on informing, advising, and providing support services. We duly respect the journal team's autonomy and do not attempt to dictate or overturn its decisions and policies.

As the leader in augmenting information literacy on campus, the library also infuses the students with a deeper understanding of such concepts as plagiarism and peer review. While the students have probably already been aware of what they mean academically, it is helpful to shepherd them to view the social and ethical sides of these concepts with reference to journal publishing. Their interpretations of them from a different perspective will enrich their academic experience and contribute to their intellectual growth.

Last but not least, the library works with the students to create the journal site and configure the online platform on the basis of the editorial workflow. We provide the students with an overview of the platform so that they can decide what functionalities they will use. As the platform is a licensed product, we introduce the students to the vendor's client support service and then act as a liaison and backup in the setup process. Thanks to the vendor's customized training Webinars, recorded online tutorials, and reference materials, the students usually do not encounter much difficulty in learning how to use the publishing system. In case they have questions, they can contact the vendor or the library for assistance.

In short, the library is well positioned to orient the students to journal publishing and to educate them about the operations of an open access journal. It assists the students with team building, policy setting, and decision making regarding the editorial workflow and practices. It provides guidance and prompts the students to make an effort to lay the groundwork for the launch and continuity of the journal.

\section{Mining Resources and Services from Other Units on Campus}

The library, as an integral part of the campus, has built extensive working relationships with different units of the university. When the students encounter problems that the library cannot resolve, we can leverage our network of working relationships to seek assistance for them. For example, while students appointed as peer reviewers are usually academically remarkable and eager to 
take on the responsibility, it is likely that they have questions about what they should pay attention to in a paper, and how they should provide comments to ensure that their reviews are adequate. In other words, their classroom learning may not have equipped them with the desirable skills for acting as reviewers. In this case, the library offers assistance to the students by identifying suitable faculty members on campus for reviewer training. There is a video recording of the training and the reviewers can view it to refresh their memory as needed.

Similarly, although alerting the students to resources about open access journal publishing helps them develop an understanding of the editorial workflow, their lack of relevant experience may prove to be a major snag in their management of the journal. As there are usually journal editors among the faculty, the library reached out and invited one to meet with the student editors. A faculty member's discussion of his/her experiences can be enlightening to the students. Meanwhile, the students can take the opportunity to seek the faculty member's advice on specific editorial issues.

In addition to providing assistance in tapping the knowledge network on campus, the library also plays a role in meeting student editors' other needs. For instance, faculty supporters for a student journal had voiced concerns over plagiarism in submitted manuscripts and strongly recommended that there be a mechanism to catch plagiarism in the editorial process. Otherwise, the publication of a plagiarized paper would simply undermine the journal's credibility. After deliberation, the student editors decided to use Turnitin to check submitted manuscripts before the review process. The university's information technology department managed the site license of Turnitin. As a unit that had an ongoing working relationship with the department, the library approached the colleagues there on behalf of the student editors and facilitated the availability and configuration of Turnitin for the journal.

Another opportunity for the library to provide assistance arose when the editors of a brand new student journal wondered about an effective means to attract potential authors from the university. The library referred them to different media outlets on campus and alerted them to appropriate student councils. There was also discussion about how other campus-based student publications could be used to source manuscripts and maximize the journal's visibility.

Even though the students often aspire to establish their journals as respectable academic publications, they may not possess the necessary skills or have access to appropriate resources for the fulfillment of their responsibilities. The library can offer help in this regard by acting as an intermediary between the students and different units on campus. Such assistance is conducive to the development of new journals. Meanwhile, it enables the library to develop a knowledge map of what resources and services are readily available on campus. In this way, the library becomes better prepared for referral services and is better informed to avoid possible duplication of effort. Moreover, as Stephen Abram remarks, mining professional networks in the provision of services is a sound and 
effective means for librarians to advocate their value and demonstrate their skills (34).

\section{Providing Support for Content Management}

The library respects the independence of the student journals and does not interfere with their editorial workflows and operations unless a prominent misstep is noticed. The library, however, is heavily involved in the journals' postproduction content management. According to Michael J. Furlough, who interviewed librarians for a study of library publishing operations, content management services "are frequently cited as a key asset for libraries engaged in publishing" (206). Indeed, the library is able to provide such services aside from offering an online platform to host the journal. For instance, when a brand new title is launched, the library requests an International Standard Serial Number for it and registers it in finding aids such as the Directory of Open Access Journals and Open J-Gate. We catalogue the journal and export the record to WorldCat so that other libraries can easily add the journal to their catalogues. As a customer of a Web-scale discovery tool, the library works with the vendor to have the journal's metadata harvested in order to increase the discoverability of the published articles. When the journal is more established, the library will investigate whether vendors of commercial databases and other Web-scale discovery tools will be interested in adding the journal content to their products. ${ }^{2}$ If the journal chooses to assign digital object identifiers (DOIs) to its articles, the library facilitates and pays for the validation of DOls. Last but not least, the library identifies possible means of archiving and preserving the journal content for long-term access. For example, Scholars Portal is a digital repository managed by the Ontario Council of University Libraries (OCUL). It is in the process of developing a long-term digital preservation service. As an OCUL member, the library has contacted Scholars Portal to explore the feasibility of having our open access journals archived and preserved there. The LOCKSS program, which is based on a decentralized approach to archiving online journal content, is another possibility that will be examined.

Meanwhile, some services are not provided directly by the library but by the vendor of the online platform. One of them is search engine optimization. It ensures that the published content is more visible in search engine result lists as long as the searcher uses relevant terms for the search. Another service is the notification of download statistics to journal editors and individual authors. The availability of such figures is of significant interest because they are indicative of how well-received a journal has been and whether efforts should be made to promote it in order to increase readership and recruit more manuscripts. In other words, the statistics constitute part of the data on which decisions for future operational activities are based.

Because of the library's expertise in organizing and managing information, we are able to provide certain services to support the content management of a 
student journal. These services help integrate the journal into the existing scholarly literature and enhance the discoverability and recognition of the published content. The students may not think of these services in the first place, but they usually appreciate them once they realize their importance.

\section{Challenges and Opportunities}

Both faculty and students maintain that the development and management of student-run research journals bring about abundant learning opportunities for students who serve on the editorial boards (Daniel Antonius et al. 33; Benjamin J. Bauer et al. 567-568). The feedback provided by the students at Western has to a large extent confirmed these assertions. However, the creation of student journals also gives rise to issues that have to be handled with care. This section addresses challenges and opportunities for the library that come with creating and hosting student journals.

While students appointed to a journal team are usually eager to work together to build the journal, some of them may become less active over time as a result of their academic pursuits and/or tight schedules in their personal lives. On the other hand, some students may be daunted by their responsibilities and may not be able to figure out how to move the journal forward. Although Richard L. Froman argues that faculty involvement is crucial in sustaining a student journal (250), the mere presence of faculty members in the journal's governance structure does not necessarily guarantee the anticipated growth because, after all, a student-run journal relies on the students' commitment to it. If the students' motivation subsides, their journal falters and its future may be in limbo. From the library's perspective, it is expected that a student journal we host is able to publish quality content in a reasonable timeframe and attract promising contributions continuously. This expectation is essential to achieving the library's goals of celebrating outstanding student research and opening up access to it. If the journal does not make progress and publish in a timely manner, all the resources and services provided to the students become questionable and might eventually be re-directed to other areas in which they can yield a better return on investment. To ensure that there is a mutually beneficial relationship between the library and the journal, the monitoring of the journal team's performance has gradually emerged as an issue. It is common that a memorandum of understanding is signed between a library and a journal when they enter into an online publishing partnership. In the case of a student journal, what terms should be stated in the memorandum to emphasize the journal team's accountability for accomplishing its mission? Given that there is already faculty involvement in the journal's governance, how can the library work with the faculty to motivate the students, to inspire a sense of leadership, to prevent the journal from stalling, and to map out a succession plan for the journal team? If sustaining the journal requires sinking more resources and services into supporting the journal team, where should the library draw the boundary? What would be the library's rights in determining the future of the journal when it was no longer satisfactorily 
operated and managed? These are some of the questions that the library has to consider when it comes to hosting a student journal.

Meanwhile, there is a need to address the scalability and sustainability of the hosting service if the number of hosted student journals increases steadily. At Western, the promotion of student research, open access, and the library's free hosting service has led to a jump in the number of hosted student journals from zero to six within two and a half years. They include four brand new titles and two previously existing journals that decided to adopt the library's online platform to publish their content. Whereas not all six journals need the same level of support, the fact that students move on and new editorial team members request training has stretched the services the library can provide. If the number of hosted journals continues to climb, the library support will be under more stress, and the hosting service should be re-considered in terms of scalability. At the same time, the library bears the costs of licensing the online platform and does not charge for the hosting service. An ongoing rise in the number of hosted journals will inevitably call into question the financial sustainability of this service model. In light of the fact that limited resources are available to support different library services, how far can this model go? In case the library decided to impose a hosting fee, would academic departments be willing to dole out funding to support the publishing of journals run by their students? As Andrea Kosavic writes when discussing the digital journal project at her library, "[t]he question of whether to charge for journal hosting is a complicated one" (319). It is indeed. Nonetheless, the library has laid down a policy in this regard and will review it as needed to ensure that the hosting service is financially sustainable. In the meantime, there emerges a need to review the performance of the four newly launched journals in order to generate suitable criteria to evaluate new proposals for creating and hosting brand new student journals. Such criteria will certainly help the library tackle the scalability and sustainability issues. In fact, these two issues are pertinent to the library's hosting service for open access journals, eBooks, and conference proceedings. They need to be revisited periodically in order to maintain the viability of the service. ${ }^{3}$

Despite these challenges, hosting student journals yields substantial benefits and opportunities. The past few years witnessed campaigns to educate students about open access, copyright, and Creative Commons licenses. SPARC (Scholarly Publishing and Academic Resources Coalition) has been an avid organizer of such campaigns, as shown by their sponsorship for the Right to Research Coalition and the Sparky Awards. Working with students to plan and develop a journal provides unparallelled opportunities to educate them about these topics. The library can also take this chance to inform the journal's faculty advisors of non-traditional practices in journal publishing. If the students work as research or teaching assistants, they might bring the topics to their academic advisors' attention and refer them to the library for more information.

Furthermore, most of the students who serve on the journal team say that they intend to pursue graduate degrees (if they are not already doing so) and wish to 
develop their careers in academia down the road. If they understand and have firm belief in the advantages of open access and author rights, they may advocate changes for a more open scholarly communication system when they become researchers or faculty members. In other words, hosting student journals can be viewed as a means to conduct scholarly communication outreach to students, who in turn may spread the word about alternative scholarly publishing practices to their peers and academic advisors. It is also instrumental in grooming future champions for positive changes in scholarly communication.

In addition, hosting student journals demonstrates how the library is able to support learning and student research in an unprecedented fashion. Developing and managing a journal prompts students to acquire skills that are not commonly addressed in the classroom. For example, those who take on the responsibilities of editors or peer reviewers have to learn how to evaluate academic writings and provide constructive criticism in the review process. They also have to work on planning, prioritizing, marketing, and time management. These skills are complementary to traditional classroom learning and will prove beneficial to the students' academic pursuits and even future professional development. As discussed earlier in this article, the library can assume an active role to facilitate this kind of learning by organizing training or information sessions. At the same time, the library's support for student research is no longer limited to providing resources and information literacy instruction. Now the library is able to offer assistance in establishing legitimate online avenues to highlight and disseminate outstanding student research. The publication of student works is a recognition of the authors' academic achievements and renders their educational experiences more gratifying. For undergraduates, it serves as an incentive for engaging in research as part of their university careers. This certainly aligns well with Western's commitment to providing the best student experience in a research-intensive environment. In short, hosting student journals offers the library a novel way to concretely demonstrate its value in supporting learning and student research. It is not only endorsed by the library but is well-received by faculty members and university administrators. When discussing the future of academic libraries, Scott Walter brings up the concept of "service turn" and argues that the definition of excellence for a library is predicated on its parent institution's service needs (7). If an institution aims to strengthen its reputation for quality education and student research, the services of providing assistance in creating and hosting student-run research journals can potentially become one of the "distinctive signifiers of excellence" for its library.

\section{Conclusion}

As the technology of online journal publishing has become widely available, some academic libraries have seized the opportunity and developed new services for journal hosting. A subset of such services is targeted at student-run research journals that are based at the libraries' parent institutions. The experience of hosting student journals at Western reveals that the library can 
assume an active role in assisting students with the creation and development of their journals. In addition to providing an online platform to host the journals, the library can guide students through the stage of team building and policy setting. Blessed by its professional networks in the university, the library can connect students with appropriate campus units in order to secure the resources and services required for the journal operations. Furthermore, the library is poised to provide services related to the management of journal content. However, the library has to handle issues such as monitoring journal teams' performance as well as heeding the scalability and financial sustainability of the hosting service. Nevertheless, the service also presents opportunities for the library to educate students about scholarly communication issues and to substantively demonstrate its value to the university. As a relatively new initiative, the provision of journal hosting service at Western is definitely a work in progress. The library will continue to review and fine-tune its policies and practices in light of the lessons learned and recommendations from others. It will also assess its experience in creating and hosting student journals and draw up an appropriate strategy for its future involvement in this regard. In the long run, the library will strive to be the preferred host of student journals to be launched at the university. We will also invite the existing print student journals on campus to adopt the library's platform to create their online presence and extend their reach to readers worldwide.

With the number of student research journals rising over time, there emerge opportunities to study issues related to running them. Different approaches to operating student journals have been discussed in the literature. While the student-run model is common, Richard L. Froman as well as Julie A. Pearson, Ronald L. VanNest, and Donna M. Jasinski describe in their articles respectively how faculty members take charge in the operations of student journals. Meanwhile, Neil Morris and Cathy Kennedy provide an overview of an entirely different managerial approach in their presentation about a faculty-run national undergraduate journal in the U.K. Yet another model is brought to light when Tabatha A. Farney and Suzanne L. Byerley write about how their library runs a student journal. What are the pros and cons of these operational models? Is their viability tied to the institutional context? Do any of them readily lend themselves to supporting teaching and curriculum integration? Are there best practices that are applicable across the board? Or does the disciplinary culture exert influence on how a student journal should be managed? What is the niche for the library in these models? Rigorous research will help answer these questions and prove useful to those who consider launching new student journals.

For student-run journals, Daniel Antonius et al. and John R. Jungck et al. argue that students gain much academically by virtue of their involvement with the editorial work. Mark E. Ware and Susan R. Burns, on the other hand, report the benefits to students when they contribute their works to student journals. It will be worthwhile to determine what (positive) effects there are for students who have either served on editorial boards or submitted papers to student journals. $A$ 
methodical assessment of the effects will produce a clear understanding of the value of student journals in higher education, which in turn may justify better support for the operations of the journals. Moreover, it will provide guidance for the library to align its resources and services to enhance the positive effects.

In the discussion of how their journal evolved, Benjamin J. Bauer et al. mention the assistance proffered by the student honour society of a professional organization. Similarly, Neil Morris and Cathy Kennedy note that learned societies sponsor the sustenance of a national undergraduate journal. What roles can scholarly and professional societies play in the creation and management of student journals? What conditions are conducive to securing sponsorship from the societies? Would they favour any particular operational model? Would there be an opportunity for the library to become a partner in a society-sponsored student journal? If it is believed that scholarly and professional societies should be more integrated into students' intellectual growth, these questions will warrant examination.

\section{Notes}

1. The library hosts both student-run and faculty-run journals. The focus of this article is on student-run research journals only because the process of creating and developing a studentrun journal usually demands more time and effort.

2. The author has discussed with some database vendors the idea of having student-run journals indexed by their databases. Their general reaction is that such journals would be of limited appeal to database users, especially when they are in the nascent stage.

3. The professional development of the staff providing the hosting service is also an issue. Michael J. Furlough notes in his study that professional development in the publishing industry "relies heavily on the apprenticeship model," and that the lack of a professional network among "publishing librarians" has reduced the opportunity for them to share knowledge and collaborate (220). Since this issue is not tied to hosting student journals per se, it is not addressed in this article. 


\section{Works Cited}

Abram, Stephen. "Advocating for Yourself." Information Outlook 15.6 (2011): 34. Print.

Antonius, Daniel, et al. "Integrating Science in Applied Psychology Programs: A Student-Operated Journal." Teaching of Psychology 34.1 (2007): 31-34. Academic Search Complete. Web. 20 Feb. 2011.

Bailey, Charles W., Jr. "A Look Back at 21 Years as an Open Access Publisher." Digital Scholarship. Charles W. Bailey, Jr., 2010. Web. 28 Dec. 2010.

Bauer, Benjamin J., et al. "Learning through Publishing The Pi Sigma Alpha Undergraduate Journal of Politics." PS: Political Science \& Politics 42.3 (2009): 565-569. Web. 20 Feb. 2011.

Bittman, Marilyn, Lindsay Lynch, and Naomi Pauls. Best Practices Guide to Scholarly Journal Publishing. Vancouver: Canadian Association of Learned Journals, 2007. Print.

Co-Action Publishing, and Lund University Libraries. Online Guide to Open Access Journals Publishing. N.d. Web. 20 Feb. 2011.

Farney, Tabatha A., and Suzanne L. Byerley. "Publishing a Student Research Journal: A Case Study." portal: Libraries and the Academy 10.3 (2010): 323-335. Project MUSE. Web. 20 Feb. 2011.

Froman, Richard L. "The Use of Locally Published Journals to Encourage Undergraduate Research." Developing, Promoting, \& Sustaining the Undergraduate Research Experience in Psychology. Eds. Richard L. Miller et al. Society for the Teaching of Psychology, 2008. 248-252. Web. 28 Feb. 2011.

Furlough, Michael J. "The Publisher in the Library." The Expert Library: Staffing, Sustaining, and Advancing the Academic Library in the $21^{\text {st }}$ Century. Eds. Scott Walter and Karen Williams. Association of College \& Research Libraries, 2010. 190-233. Print.

Gilman, Isaac, and Marita Kunkel. "From Passive to Pervasive: Changing Perceptions of the Library's Role through Intra-Campus Partnerships." Collaborative Librarianship 2.1 (2010): 22-32. Web. 20 Feb. 2011.

Hahn, Karla, L. Research Library Publishing Services: New Options for University Publishing. Association of Research Libraries, 2008. Web. 2 Jan. 2011. 
Harboe-Ree, Catherine. "Just Advanced Librarianship: The Role of Academic Libraries as Publishers." Australian Academic \& Research Libraries 38.1 (2007): 15-25. Academic Search Complete. Web. 20 Feb. 2011.

Hodgson, Justin. "Making the Jump: Digital Publishing and Collaboration." EDUCAUSE Quarterly 34.3 (2011): N.p. Web. 2 Oct. 2011.

Jankowska, Maria Anna. "A Library's Contribution to Scholarly Communication and Environmental Literacy: The Case of an Open-Access Environmental Journal." The Serials Librarian 49.4 (2006): 117-124. Web. 12 Nov. 2010.

Jungck, John R., et al. "Undergraduates: Do Research, Publish!" Cell Biology Education 3.1 (2004): 24-26. Web. 20 Feb. 2011.

Kosavic, Andrea. "The York Digital Journals Project: Strategies for Institutional Open Journal Systems Implementation." College \& Research Libraries 71.4 (2010): 310-321. Print.

Lund University Libraries. Directory of Open Access Journals. 2011. Web. 20 April 2011.

Morris, Neil, and Cathy Kennedy. "National Undergraduate Bioscience Research Journal." Science Online London 2011. Web (online video). 20 Sept. 2011.

Pearson, Julie A., Ronald L. VanNest, and Donna M. Jasinski. "Promoting Publication by Producing a Student Journal." Nurse Educator 29.2 (2004): 68-70. Web. 20 Feb. 2011.

Phillips, Linda L. "Coming Home: Scholarly Publishing Returns to the University." Transforming Research Libraries for the Global Knowledge Society. Ed. Barbara I. Dewey. Chandos Publishing, 2010. 147-163. Print.

Reno, Ariel. "Electronic Undergraduate Research Journals: A Survey of Their Characteristics." The Eagle Feather: A Publication for Undergraduate Scholars. 6 (2009): 1-30. Web. 20 Feb. 2011.

"Undergraduate Journals and Publications." Council on Undergraduate Research. Council on Undergraduate Research, n.d. Web. 20 April 2011.

Walter, Scott. "'Distinctive Signifiers of Excellence": Library Services and the Future of the Academic Library." College \& Research Libraries 72.1 (2011): 6-8. Print.

Ware, Mark E., and Susan R. Burns. "Undergraduate Student Research Journals: Opportunities for and Benefits from Publication." Developing, 
Promoting, \& Sustaining the Undergraduate Research Experience in Psychology. Eds. Richard L. Miller et al. Society for the Teaching of Psychology, 2008. 253-256. Web. 28 Feb. 2011.

Western Libraries. Western Libraries: Library-as-Place \& Place-as-Library Strategic Plan 2007-08 - 2010-11. Web. 12 Nov. 2010.

Xia, Jingfeng. "Library Publishing as a New Model of Scholarly Communication." Journal of Scholarly Publishing 40.4 (2009): 370-383. Web. 20 Feb. 2011. 


\section{Appendix: Online Resources Mentioned in Article}

Council on Undergraduate Research: http://www.cur.org/

Council on Undergraduate Research's list of undergraduate journals:

http://www.cur.org/ugjournal.html

Creative Commons licenses: http://creativecommons.org/licenses/

Developing Open Access Journals: http://www.developing-oa-journals.org/

Directory of Open Access Journals: http://www.doaj.org/

LOCKSS (Lots of Copies Keep Stuff Safe): http://www.lockss.org/

National Undergraduate Bioscience Research Journal:

http://www.youtube.com/watch?v=y taf93Vdpk

Online Guide to Open Access Journals Publishing: http://www.doaj.org/bpguide/

Open J-Gate: http://www.openj-gate.com/

Right to Research Coalition: http://www.righttoresearch.org/

Scholars Portal: http://www.scholarsportal.info/

Scholarship@Western: http://ir.lib.uwo.ca/

SPARC (Scholarly Publishing and Academic Resources Coalition):

http://www.arl.org/sparc/

Sparky Awards: http://www.sparkyawards.org/

Student Reviewer Training for Western Undergraduate Research Journal: Health and Natural Sciences: http://ir.lib.uwo.ca/wlevents/3/

WorldCat: http://www.worldcat.org/ 